\title{
Sosialisasi Kiat Penanaman dan Pemasaran Hidroponik Untuk Meningkatkan Pendapatan Keluarga Kelurahan Teluk Pucung Kecamatan Bekasi Utara-Kota Bekasi
}

\author{
Endah Prawesti Ningrum ${ }^{1, *}$, Matdio Siahaan ${ }^{1}$, Ridwan Anwar ${ }^{1}$ \\ ${ }^{1}$ Fakultas Ekonomi dan Bisnis; Universitas Bhayangkara Jakarta Raya;Jl. Raya Perjuangan, \\ Marga Mulya, Bekasi Utara, Jawa Barat 17121. Telp:021-88955882, 889955883; e-mail: \\ endah.prawesti@dsn.ubharajaya.ac.id, matdio.siahaan@dsn.ubharajaya.ac.id, \\ ridwan.anwar@dsn.ubharajaya.ac.id \\ *Korespondensi: e-mail: endah.prawesti@dsn.ubharajaya.ac.id
}

Submitted: 27/06/2021; Revised: 10/01/2021; Accepted: 17/01/2021; Published: 29/01/2021

\begin{abstract}
Teluk Pucung is a sub-district located in North Bekasi sub-district, Bekasi City, West Java, Indonesia which has a high population density, especially for housing, public facilities and infrastructure, and only a small amount a little gardening. Because of this, this community service activity aims to build community independence so that it can develop the potential of the surrounding environment, especially entrepreneurial programs to increase family income. So, it is hoped that the growth of entrepreneurial independence through the application of hydroponic agriculture can be maximally applied, besides that they can independently provide for foodstuffs from agriculture and economically can be used as a productive economic business on a household scale considering the strategic position of Bekasi City which is directly adjacent to the Jakarta city. This is of course so that the existence of a prosperous community life in a city that functions as a residential city is a residential city which is the existence of green open space. This method of community service activities uses lectures or outreach, discussion and learning methods that are practiced by participants and resource persons. The lecture method is used to convey general knowledge about hydroponic cultivation and entrepreneurial development. The learning method is used to transfer the knowledge and skills possessed by the resource person to community members. This training involves lecturers at the Bhayangkara Jakarta Raya Bekasi University in collaboration with the community members of Kel. Teluk Pucung.
\end{abstract}

Keywords: Entrepreneurship, Family Income and Hydroponic Socialization

\begin{abstract}
Abstrak
Teluk Pucung adalah kelurahan yang berada di kecamatan Bekasi Utara, Kota Bekasi, Jawa Barat, Indonesia yang memiliki kepadatan penduduk yang tinggi, digunakan untuk membangun perumahan, toko-toko, dan sedikit lahan untuk berkebun. Oleh karena hal tersebut, kegiatan ini bertujuan untuk membangun kemandirian masyarakat agar dapat mengembangkan potensi lingkungan sekitarnya terutama program kewirausahaan untuk menambah pendapatan keluarga. Maka, diharapakan penumbuhan kemandirian berwirausaha melalui penerapan pertanian hidroponik dapat diterapkan secara maksimal, selain itu mereka dapat secara mandiri menyediakan kebutuhan bahan pangan asal pertanian dan secara ekonomi dapat dijadikan usaha ekonomi produktif pada skala rumah tangga mengingat posisi strategis Kota Bekasi ini yang berdekatan langsung dengan wilayah kota Jakarta. Hal ini tentunya agar berajlannya suatu kehidupan masyarakat yang sejahtera di dalam kota yang berfungsi sebagai kota hunian yang merupakan kota hunian yang merupakan keberadaan dari ruang terbuka hijau. Metode kegiatan abdimas ini menggunakan metode penyuluhan, diskusi dan pembelajaran yang dipraktekkan oleh peserta dan narasumber. Metode ceramah digunakan untuk menyampaikan
\end{abstract}


pengetahuan secara umum tentang penanaman hidroponik dan pengembangan kewirausahaan. Metode pembelajaran digunakan untuk alih pengetahuan dan ketrampilan yang dimiliki oleh narasumber kepada anggota masyarakat. Pelatihan ini melibatkan dosen-dosen fakultas ekonomi dan bisnis Universitas Bhayangkara Bekasi yang bekerjasama dengan warga masyarakat Kel. Teluk Pucung.

Kata kunci: Kewirausahaan, Penghasilan Keluarga dan Sosialisasi Hidroponik

\section{Pendahuluan}

Teluk Pucung adalah kelurahan yang berada di kecamatan Bekasi Utara, Kota Bekasi, Jawa Barat, Indonesia, yang memiliki luas wilayah 1.987.124 Ha / 22 km2 dengan jumlah penduduk sebanyak 373.054 jiwa, dan jumlah KK sebanyak 84.061 KK (Monografi kecamatan Bekasi Utara 2017).

Tabel 1. Jumlah Penduduk Menurut per-Kecamatan Kota Bekasi 2016

\begin{tabular}{ll}
\hline \multicolumn{1}{c}{ Nama Kecamatan } & Jumlah Penduduk (Jiwa) \\
\hline Pondok Gede & 298.075 \\
\hline Jatisampurna & 141.479 \\
\hline Pondok Melati & 155.407 \\
\hline Jatiasih & 244.207 \\
\hline Bantargebang & 115.230 \\
\hline Mustika Jaya & 243.917 \\
\hline Bekasi Timur & 259.879 \\
\hline Rawalumbu & 256.622 \\
\hline Bekasi Selatan & 227.246 \\
\hline Bekasi Barat & 299.180 \\
\hline Medan Satria & 184.987 \\
\hline Bekasi Utara & 373.054 \\
\hline Sumber: BPS Bekasi (2017) &
\end{tabular}

Berdasarkan tabel jumlah penduduk perkecamatan di kota Bekasi, kecamatan yang memiliki jumlah penduduk tertinggi adalah kecamatan Bekasi Utara. Kecamatan Bekasi Utara tercatatkan memiliki jumlah penduduk sebesar 373.054 jiwa, sedangkan Kecamatan Bantar Gebang adalah kecamatan yang memiliki jumlah penduduk terdikit jika dibandingkan dengan kecamatan kecamatan lainnya. Berdasarkan tabel diatas mencatatkan jumlah penduduk di Kecamatan bantar Gebang sebesar 115.230 jiwa.

Dengan banyaknya penduduk, maka banyak lahan digunakan untuk membangun gedung, took-toko, dan lainnya, serta sedikit saja lahan untuk berkebun (Wahyuningsih et al, 2016). Saat ini berkebun hidroponik adalah solusi yang baik untuk menghasilkan perkebunan di pekarangan yang terbatas. Keunggulan berkebun hidroponik yaitu higienisnya tanaman lebih mudah dijaga, alas yang steril, menggunakan air dan pupuk yang sangat efektif, tanaman dapat dilestarikan tanpa mengkhawatirkan kondisi, dapat digunakan pada pekarangan terbatas, serta aman dari panas dan hujan (Silvina et al, 2008). 
Penambahan nutrisi yang dibutuhkan untuk hidroponik, yaitu nutrisi yang baik. Nutrisi hidroponik tersedia di supermarket-supermarket atau pertokoan yang digunakan dan biasa digunakan untuk memupuk tanaman. Cairan nutris terdiri atas garam-garam makro dan mikro yang dibuat dalam larutan stok A dan B (Samanhudi et al, 2010). Sistem ini bisa dilakukan di pekarangan yang terbatas di wilayah kota (Purwasih, 2019). Sistem ini memiliki banyak keunggulan, salah satunya yaitu tanaman hidroponik dapat digunakan pada ruang yang terbatas misalnya di celah sempit seperti teras, dapur atau garasi, selain itu perawatan tanaman pada sistem hidroponik lebih praktis dan gangguan hama lebih terkontrol (Roidah, 2014) . Kebutuhan hasil perkebunan semakin naik sejalan dengan kepadatan jumlah penduduk yang semakin meningkat, sementara kemajuan teknologi semakin tinggi yang mengakibatkan pertanian semakin terbatas. Maka, diharapkan penumbuhan minat berwirausaha melalui penerapan pertanian hidroponik dapat diterapkan secara maksimal, selain itu mereka dapat secara mandiri menyediakan kebutuhan bahan pangan asal pertanian dan secara ekonomi dapat dijadikan usaha ekonomi produktif pada skala rumah tangga mengingat posisi strategis Kota Bekasi ini yang berdekatan langsung dengan wilayah kota Jakarta. Hal ini tentunya agar berjalannya suatu kehidupan masyarakat yang sejahtera di dalam kota yang berfungsi sebagai kota hunian yang merupakan keberadaan dari ruang terbuka hijau.

Salah satu hal yang dilakukan untuk klasifikasi adalah demografi masyarakat. Kebutuhan pokok berupa sayuran merupakan bahan pokok yang paling utama bagi warga masyarakat. Kebutuhan mendasar manusia dikembangkan oleh Maslow, hal ini agak berbeda karena sayuran yang belum banyak dikonsumsi warga dan termasuk klasifikasi kebutuhan sayur mayor yang berharga relative mahal (hanya ada di supermarket dan hypermarket). Percepatan demografi dan perilaku konsumen menjadikan kegiatan pemenuhan kebutuhan kenaikan akan bahan pokok sayur mayur ini akhirnya dipahami oleh para penjual sayuran khususnya pengusaha sayuran hidroponik. Pemenuhan kebutuhan pokok sayuran bagi konsumen akan memiliki pandangan yang lain, dimana beberapa konsumen beranggapan bahwa sayur mayor dengan hidroponik adalah kebutuhan dan sebagian lagi menilai bahwa sayuran hidroponik tersebut adalah hanyalah sebuah keinginan semata. Sadar bahwa ini adalah produk pangan dengan spesifikasi khusus, belum menjadi produk pangan yang utama bagi masyarakat, masih rendahnya kesadaran masyarakat untuk hidup sehat, termasuk dalam convenience good dan terbatasnya faktor produksi (lahan), maka menjadi sangat menarik ketika pengusaha hidroponik ini mampu mencapai maksimalisasi penjualan dan mampu memasarkan produk sayuran hidroponiknya.

Fenomena terjadinya perubahan konsumen dalam mengklasifikasikan bahwa ini adalah kebutuhan dan keinginan, perlu ditanggapi dengan mengkaji faktor demografi dan phisikografi konsumen. Kegiatan mengidentifikasi segmen berdasarkan faktor demografi dan phisikografi sekaligus menentukan pasar sasaran ini harus dilakukan oleh pengusaha hidroponik bahkan sebelum keputusan memulai usaha hidroponik ini diambil. Akhirnya, setelah mampu menghasilkan sayuran hidroponik yang unggul, keuntungan maksimal yang diharapkan dari 
keberhasilan pemasaran akan segera terwujud. Hal yang sangat penting dalam mengusahakan jenis usaha apapun khususnya hidroponik adalah memikirkan strategi pemasaran. Adapun strategi pemasaran yang harus dipikirkan adalah 1) Menentukan target pemasaran; menentukan ke mana produk tersebut akan dijual. Hal ini sangat penting karena dengan demikian produksi yang akan kita hasilkan terukur dan target sesuai pesanan, 2) merencanakan produk; hal ini akan menjadi mudah jika kita sudah mempunyai target pasar, sehingga kita akan fokus pada jumlah produksi, kemasan, dan menentukkan strategi promosi agar mampu bersaing dengan produsen lain, 3) menentukan harga jual; harga merupakan komponen paling penting dalam dunia persaingan, 4) menyusun strategi distribusi; distribusi merupakan usaha untuk memindahkan produk langsung ke konsumen. Distribusi harus disesuaikan dengan keinginan konsumen, untuk itu kita harus memiliki strategi distribusi yang memuaskan konsumen, dan 5) promosi; merupakan cara untuk memperkenalkan produk ke calon konsumen. Hal ini bisa dilakukan dengan cara membuat brosurdan melakukan presentase yang disertai dengan sampel dari produk. Promosi juga bisa dilakukan dengan cara online.

Dalam memasarkan sayuran hidroponik, salah satu alternatif memasarkan produk hidroponik adalah 1) mencoba menjalin kerjasama dengan koperasi tani terdekat untuk bisa menjual produk ke koperasi. Penjualan ke koperasi tani akan memudahkan kita dalam melakukan transaksi sebab bisa menjual hasil hidroponik tanpa ada batasan jumlahnya meskipun harga belinya tidak sebagus di pasaran, 2) Memasok ke cafe dan restaurant; cara ini mengharuskan kita untuk bergabung dengan komunitas para penjual sayuran hidroponik yang memang juga bekerjasama dengan pihak cafe. Cara memasarkan hidroponik semacam ini akan memudahkan kita menjual hasil hidroponik meskipun hanya menghasilkan sedikit, 3) Menawarkan ke pasar tradisional; beberapa petani hidroponik yang tidak memungkinkan untuk panen setiap hari mencoba untuk mencari solusi permasalahannya dengan menjual hasil panennya ke pasar tradisional. Cara memasarkannya produk hidroponik semacam ini bisa dilakukan ketika kita menemukan pengepul yang bersedia menerima sayuran hidroponik tersebut. Namun harus tetap memperhatikan kualitas dan kebersihan dari sayuran tersebut, 4) Menjual langsung dari kebun (Kalimanun, 2018).

Didasari permasalahan tersebut, kami dari tim dosen terpanggil untuk melaksanakan penyuluhan tentang penanaman hidroponik untuk membagi pengetahuan dan keterampilan dengan tujuan kami masyarakat mampu meneruskan usaha tersebut dan menambah pendapatan keluarga (Utama et al, 2006). Dengan dilaksanakannya pengabdian kepada masyarakat ini memberikan pengetahuan dan ketrampilan yang bermanfaat bagi pengurus lingkungan mulai dari Pengurus RT sampai di tingkat kelurahan. Tujuan Kegiatan adalah untuk memberikan pengetahuan dan ketrampilan dalam penanaman hidroponik dan penggunaan penanaman hidroponik sebagai peluang usaha untuk berwirausaha (Zainuddin et al, 2018). Manfaat kegiatan adalah : dapat menambah pengetahuan dan ketrampilan dalam penanaman 
hidroponik dan program ini dapat dikembangkan kepada masyarakat atau kelurahan yang lain supaya dapat menciptakan kenyamanan dan keindahan lingkungan (Kaunang et al, 2016).

\section{Metode Pelaksanaan}

Dalam menunjang kegiatan pelaksanaan pengabdian masyarakat ini. Berikut ini adalah rincian metode yang akan dilakukan, yaitu 1) Metode Pengumpulan data. Hal ini digunakan untuk mengumpulkan data-data mengenai kegiatan yang dilakukan pada masyarakat RT/RW, Kel. Teluk Pucung, Kec. Bekasi Utara yang akan diselenggarakan pengabdian masyarakat. Kriteria pemilihan lokasi PKM yaitu lokasi yang dijadikan KKN Reguler Universitas Bhayangkara Jakarta Raya Bekasi; 2) Menentukan tema pengabdian yang akan diberikan. Berdasarkan hasil survei yang diuraikan secara rinci kemudian tema pengabdian segera ditentukan yaitu penanaman hidroponik sebagai peluang usaha untuk meningkatkan pendapatan keluarga di Kel. Teluk Pucung, Kec. Bekasi Utara Kota Bekasi; 3) Mencari Studi Pustaka. Studi pustaka adalah teknik pengumpulan data referensi dari berbagai jenis sumber keilmuan yang menunjang permasalahan yang sedang dicarikan solusinya. Dalam kegiatan pengabdian masyarakat ini, berbagai teori dan implementasi tentang tema pengabdian untuk dapat memberikan pemahaman yang signifikan; 4) Membuat materi pelatihan. Berdasarkan studi pustaka yang telah dilakukan maka dibuatlah materi penyuluhan dan pelatihan kewirausahaan; 5) Menyajikan pelatihan. Pelatihan diberikan secara tutorial antara instruktur dengan peserta yang langsung didemokan pada peserta pengabdian masyarakat. Luaran yang akan dihasilkan dalam kegiatan ini adalah dengan adanya pasca kegiatan PKM ini diharapkan dapat memberikan perubahan sebagai berikut 1) Masyarakat mendapatkan pengetahuan mengenai penanaman hidroponik dan kewirausahaan tentang apa dan bagaimana menciptakan peluang usaha dan mengembangkan potensi lingkungan yang sudah ada di wilayah Kelurahan Jati Teluk Pucung Kecamatan Bekasi Utara Kota Bekasi; 2) Warga Kelurahan Teluk Pucung mendapat bekal keterampilan praktis dalam menjalankan usaha hidroponik kewirausahaan yang dijalankan.

\section{Hasil dan Pembahasan}

Pelaksanaan pelatihan pada bulan Februari 2020 berjalan dengan lancar. Materi pertama yang diberikan adalah pengenalan atau penyuluhan mengenai pemanfaatan tanaman hidroponik. Sebagian besar audiens belum mengerti arti pentingnya melakukan penanaman hidroponik, bahkan sebagian besar peserta pelatihan menganggap bahwa melakukan penanaman hidroponik adalah bidang yang rumit, susah, merepotkan, menghabiskan waktu.

Pada sesi ini terjadi diskusi yang menarik antara audiens dengan pemateri mengenai konsep dasar penanaman hidroponik. Beberapa audiens memiliki persepsi berbeda tentang penggunaan lahan hidroponik yang terbatas dan cara penanamannya. Berdasarkan diskusi konsep penanaman ini akhirnya diperoleh pemahaman konsep penanaman hidroponik, dan pentingnya melakukan pemanfaatan lahan yang terbatas dengan menggiatkan tanaman 
hidroponik (Rosliani et al, 2005). Aktivitas penanaman seperti aktivitas memulai usaha (investasi awal), dengan membeli bibit tanaman, penanaman, dimana menuntut ketekunan dari para warga untuk menyiram, memupuk tanaman, menghasilkan sebuah aktivitas yang baik bagi kesehatan terkena sinar matahari secara langsung maupun tanaman hidroponik tersebut bisa dapat langsung dikonsumsi dengan aman bagi kesehatan.

Gambar 1 menunjukkan survey awal ke kantor Kelurahan Teluk Pucung dengan bertemu Kepala Kelurahan yaitu Bapak Muhamad AR.
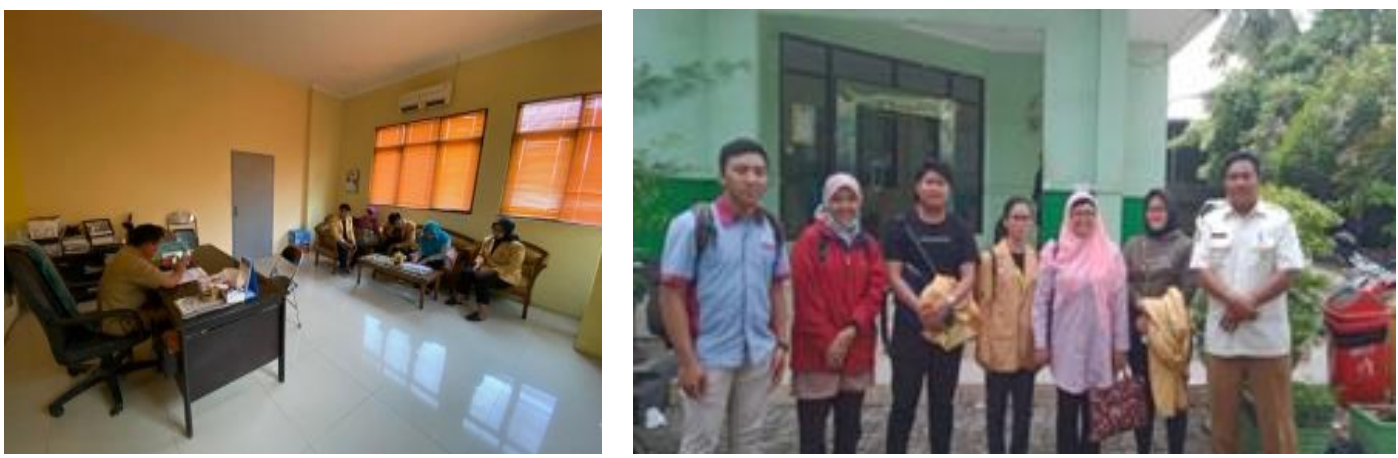

Sumber : Hasil Pelaksanaan (2020)

Gambar 1. Pertemuan dengan Ketua RW. 018 dan Pengurus RT

Gambar 2 menunjukkan dokumentasi kegiatan persiapan peralatan dan bahan yang dibutuhkan untuk membuat hidroponik bersama anggota kelurahan Teluk Pucung untuk meninjau lokasi RW. 018.
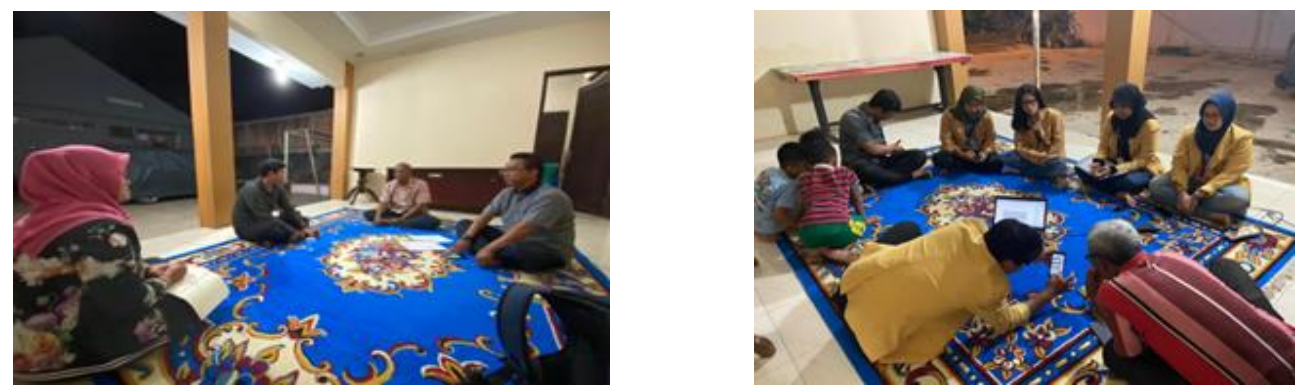

Sumber : Hasil Pelaksanaan (2020)

Gambar 2. Persiapan Peralatan Dan Bahan Yang Dibutuhkan Untuk Membuat Hidroponik

Gambar 3 menunjukkan kegiatan pengabdian kepada masyarakat dalam pembuatan alat hidroponik melalui pembolongan pipa dengan warga.

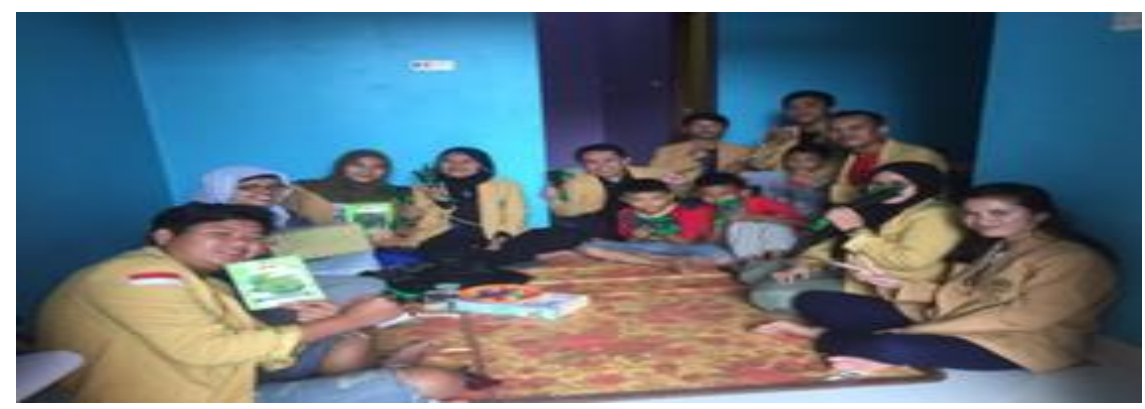

Sumber : Hasil Pelaksanaan (2020)

Gambar 3. Pembuatan Alat Hidroponik Melalui Pembolongan Pipa 
Gambar 4 menunjukkan proses penyelesaian pemasangan pipa hidroponik yang dilakukan oleh warga.

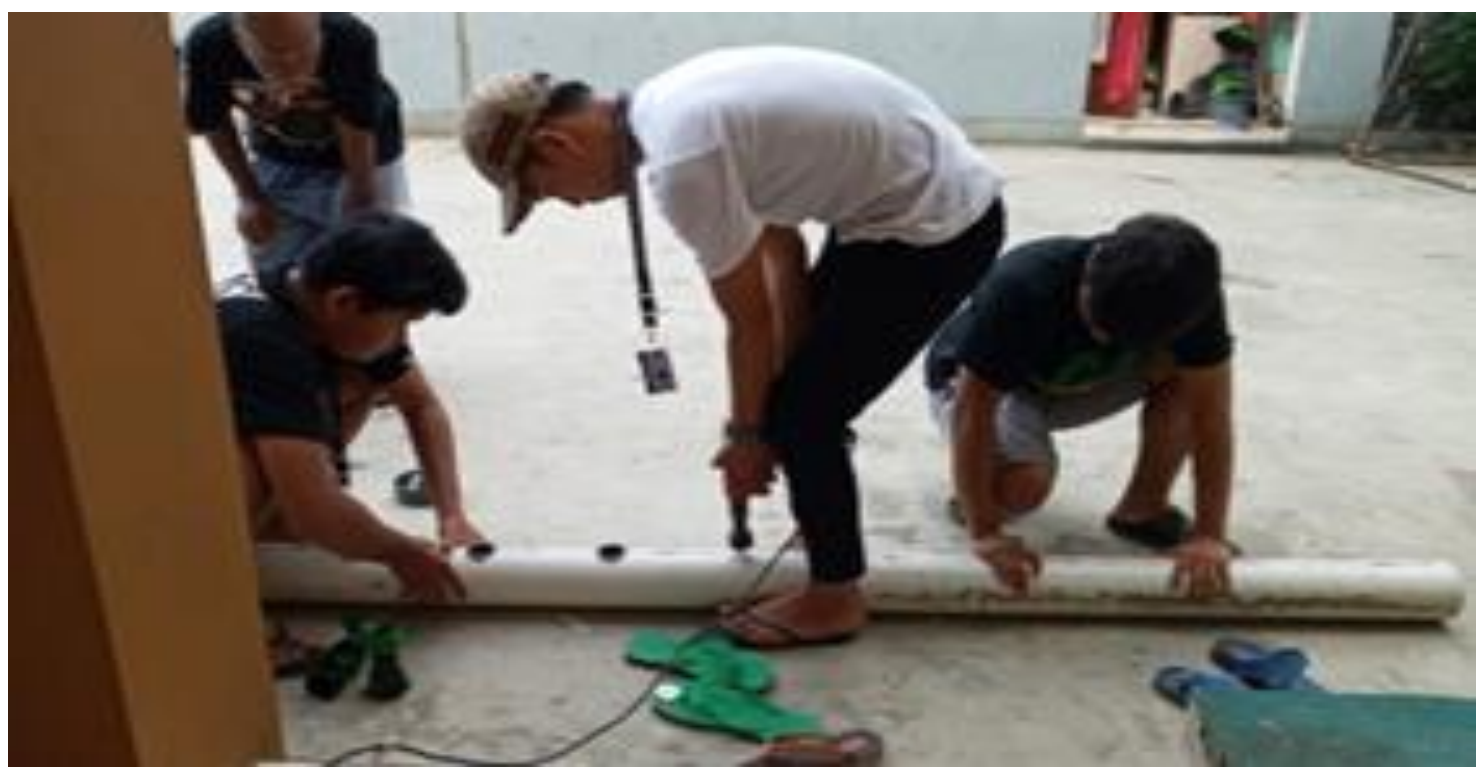

Sumber : Hasil Pelaksanaan (2020)

Gambar 4. Proses Penyelesaian Pemasangan Pipa Hidroponik

Gambar 5 menunjukkan kegiatan penyuluhan praktek kepada masyarakat mengenai proses awal persemaian hidroponik menggunakan rockwoll.

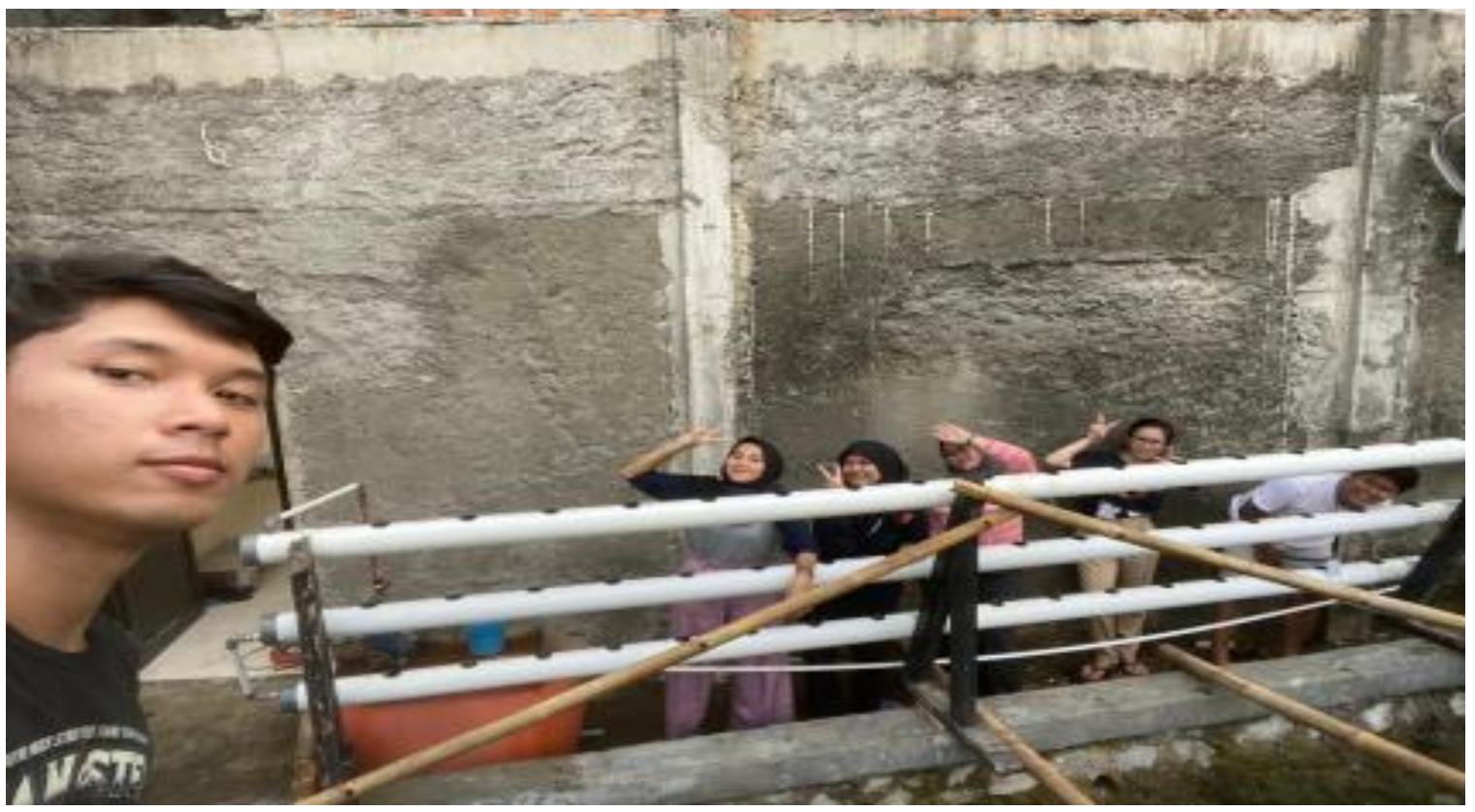

Sumber : Hasil Pelaksanaan (2020)

Gambar 5. Penyuluhan Proses Awal Persemaian Hidroponik Menggunakan Rockwoll

Gambar 6 menunjukkan kegiatan pengecekan dan pembuatan nutrisi tanaman hidroponik. 

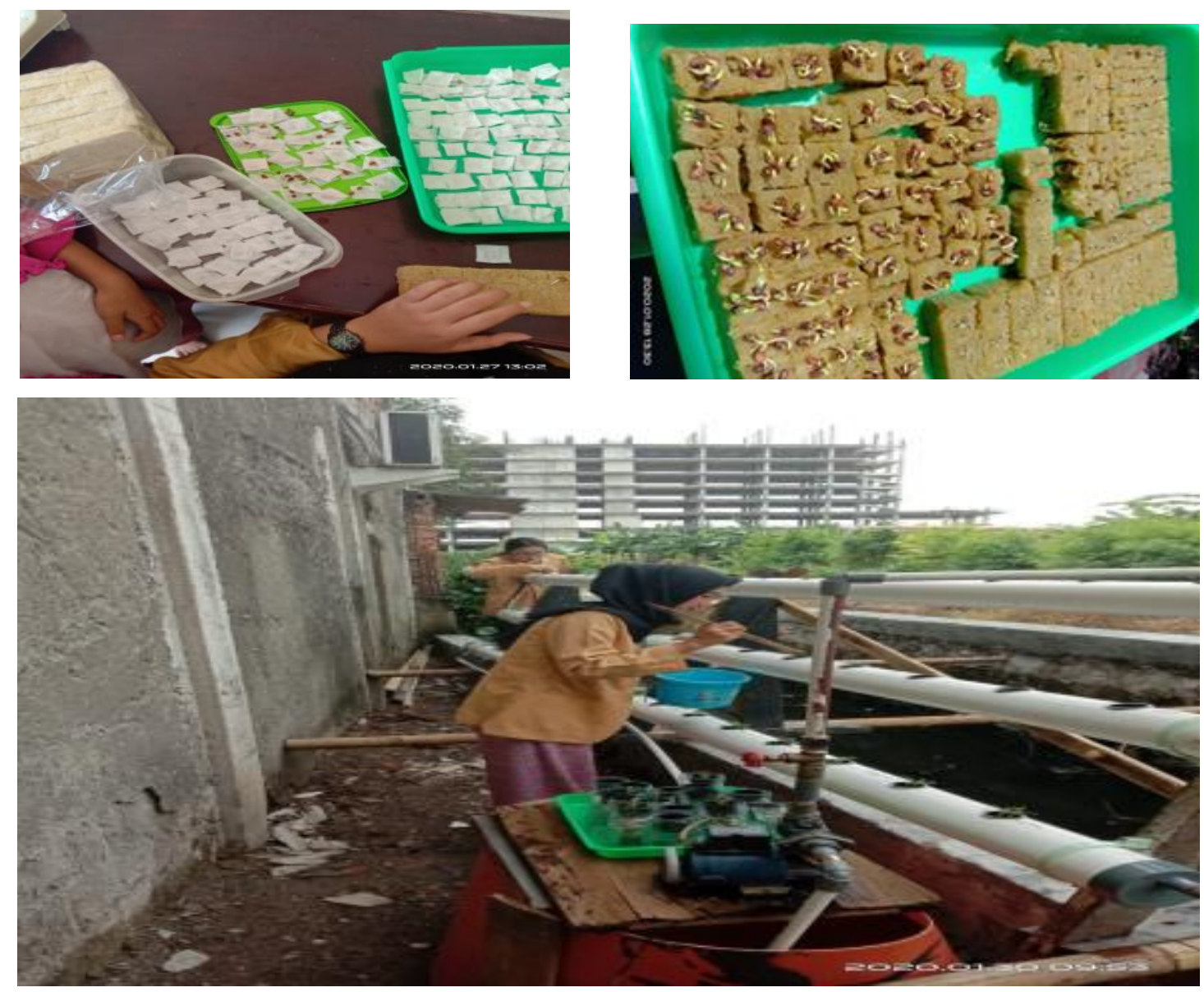

Sumber : Hasil Pelaksanaan (2020)

Gambar 6. Pengecekan Dan Pembuatan Nutrisi Tanaman Hidroponik

Gambar 7 menunjukkan penyuluhan penanaman hidroponik setelah penyemaian bibit dan ditanamkan ke dalam pot kecil.
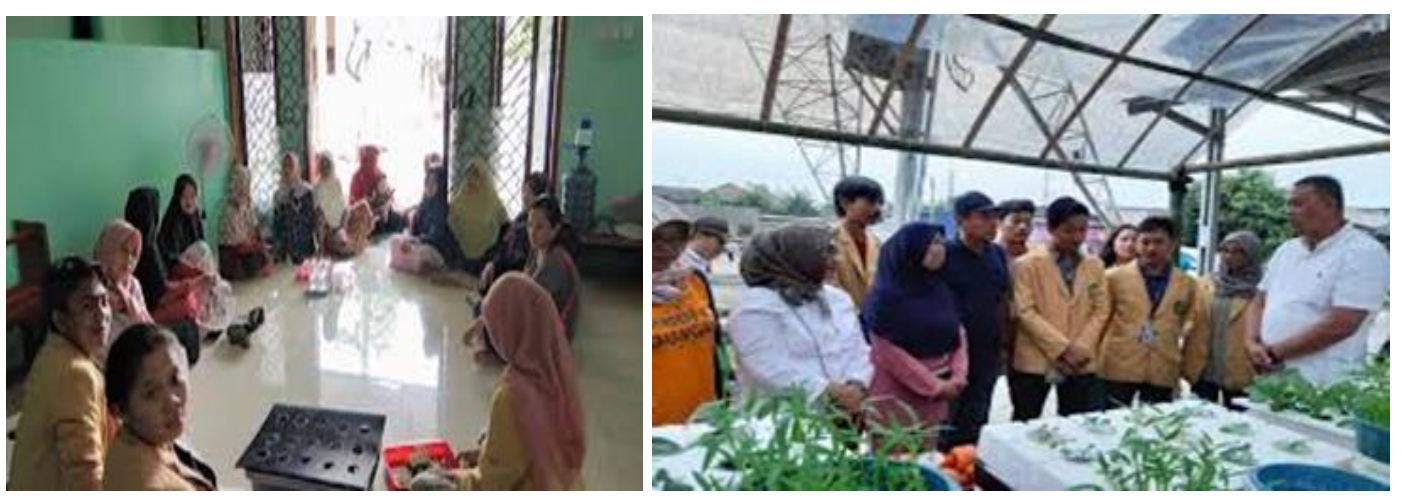

Sumber : Hasil Pelaksanaan (2020)

Gambar 7. Penyuluhan Penanaman Hidroponik

Setelah itu, materi berikutnya adalah kewirausahaan. Setelah didapatkan tanaman yang unggul dari penanaman hidroponik, hasilnya bisa langsung dikonsumsi langsung oleh warga, maupun dapat langsung dipasarkan ke warga sekitar dan juga ke pasar tradisional, bahkan bisa sampai ke supermarket jika diberi kemasan dan label yang sudah mendapat izin dari pemerintah setempat. Dari hasil penjualan penanaman hidroponik, secara tidak langsung 
berdampak positif bagi masyarakat karena warga masyarakat dapat berperan aktif menjadikan lingkungan di perumahan menjadi lebih hijau dan asri, selain itu menumbuhkan jiwa kewirausahaan dan pendapatan bagi para warga. Hal ini digambarkan dalam gambar 8 , dimana para warga dan mahasiswa berfoto setelah mendapatkan penyuluhan kewirausahaan.

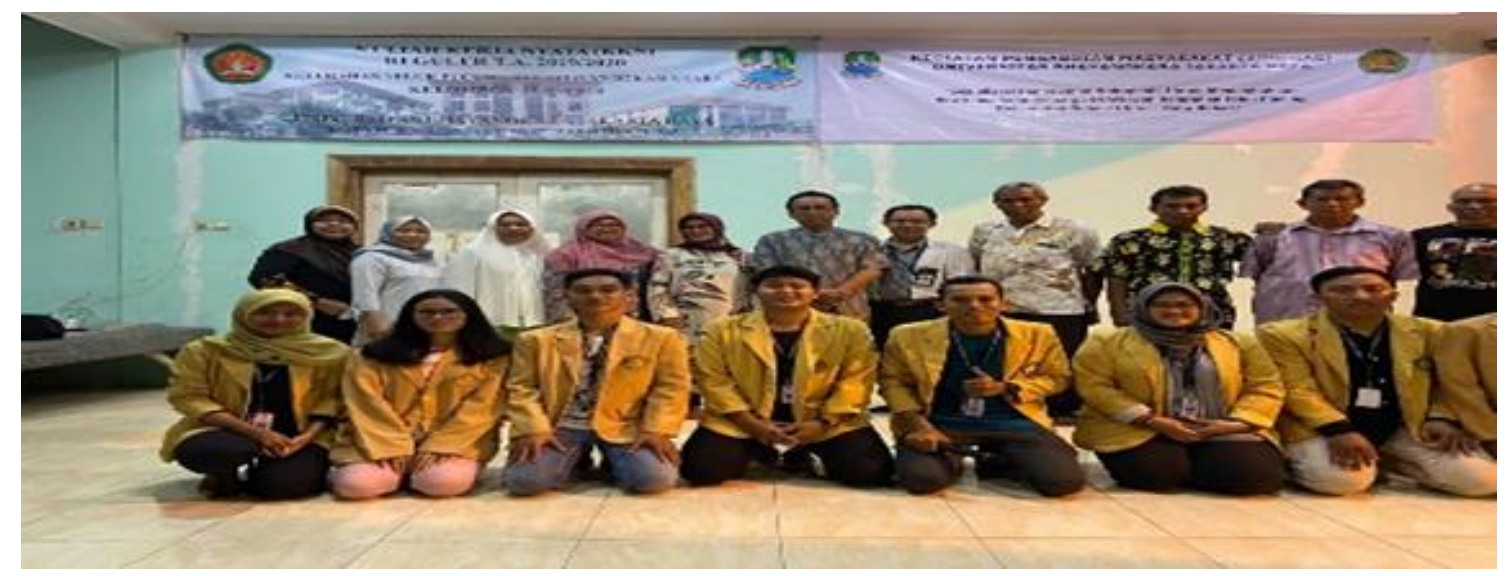

Sumber : Hasil Pelaksanaan (2020)

Gambar 7. Kegiatan Sesi Foto Bersama di Akhir Kegiatan

\section{Kesimpulan}

Program Pelatihan dapat diselenggarakan dengan baik dan berjalan dengan lancar sesuai dengan rencana kegiatan yang telah disusun meskipun belum semua peserta pelatihan menguasai dengan baik materi yang disampaikan. Kegiatan ini mendapat sambutan yang hangat dari warga masyarakat yaitu terbukti dengan keaktifan dan antusiasme pelatihan dengan melakukan pelatihan sejalan dengan arahan para penyaji. Semua warga masyarakat sangat aktif mengikuti penyuluhan abdimas hingga berakhir dan merasakan kegunaan pelatihan bagi peluang usaha warga masyarakat.

Adapun rekomendasi untuk membuat masyarakat semakin mandiri, yaitu perlu adanya koordinasi lebih lanjut, antar Kelurahan Teluk Pucung dengan warga di sekitar kelurahan teluk pucung dalam mengelola penanaman hidroponik, sangat diperlukan adanya ketekunan dan kesabaran dalam pemanfaatan tanaman hidroponik, kemudian perlu adanya perluasan jaringan dalam pemasaran hasil tanaman yang telah dihasilkan, serta pelatihan lanjutan secara periodik sehingga dapat meningkatkan kemampuan para khalayak sasaran agar tercipta kesinambungan diantara para warga dan wirausaha lainnya.

\section{Ucapan Terima Kasih}

Kami menyampaikan rasa terima kasih kepada Bapak Muhamad AR sebagai Lurah Teluk Pucung, Bapak Rw.018 dan seluruh pengurus RTnya, karena sudah membuka kesempatan bagi kami untuk membagikan sebuah wawasan mengenai pelaksanaan penanaman hidroponik dan kiat pemasaran untuk meningkatkan pendapatan keluarga di lingkungannya menggunakan media tanam hidroponik secara sederhana. Kami juga 
mengucapkan rasa terima kasih kepada seluruh warga Rw. 018, karena sudah bersedia menerima dan bersedia menerapkan hal-hal yang kami sampaikan. Begitu juga kepada seluruh mahasiswa dan juga pimpinan Universitas Bhayangkara Jakarta Raya karena telah memberikan dukungan yang berharga bagi kami untuk melaksanakan salah satu dharma sebagai dosen, melalui kegiatan pengabdian kepada masyarakat.

\section{Daftar Pustaka}

Kalimanun, J. C. (2018). Sistem Pemasaran Sayuran Hidroponik di Kalimantan Barat Hydroponic Vegetables Marketing Systemin West Kalimantan Juliana C. Kilmanun 1 Balai Pengkajian Teknologi Pertanian Kalimantan Barat. 20(2), 147-153.

Kaunang et al. (2016). Persepsi Masyarakat terhadap Tanaman Hidroponik Di Desa Lotta, Kecamatan Pinelemg, Kabupaten Minahasa. 12, 283-302.

Purwasih, R. (2019). Pemanfaatan Lahan Pekarangan untuk Budi Daya Sayuran Secara Hidroponik di Kecamatan Sungailiat, Kabupaten Bangka, Provinsi Kepulauan Bangka Belitung. Agrokreatif: Jurnal IImiah Pengabdian Kepada Masyarakat, 5(3), 195-201. https://doi.org/10.29244/agrokreatif.5.3.195-201

Roidah, I. S. (2014). Pemanfaatan Lahan Dengan Menggunakan Sistem Hidroponik. 1(2), 4350.

Rosliani et al. (2005). Budidaya Tanaman Sayuran dengan Sistem Hidroponik.

Samanhudi et al. (2010). Pengaturan Komposisi Nutrisi Dan Media Dalam Budidaya Tanaman Tomat Dengan Sistem Hidroponik. IImiah Pertanian Biofarm.

Silvina et al. (2008). Penggunaan Berbagai Medium Tanam dan Konsentrasi Pupuk Organik Cair pada Pertumbuhan dan Produksi Mentimun Jepang (Cucumis Sativus) Secara Hidroponik. Issn 1412-4424, Vol. 7, pp. 7-12. Retrieved from https://ejournal.unri.ac.id/index.php/JSG/article/view/1096/1088

Utama et al. (2006). Pemeliharaan Tanaman Hidroponik. 8(1), 1-4.

Wahyuningsih et al. (2016). Komposisi Nutrisi dan Media Tanam Terhadap Pertumbuhan dan Hasil Tanaman Pakcoy ( Brassica rapa L .). Jurnal Produksi Tanaman, 4(8), 595-601.

Zainuddin et al. (2018). Pengenalan Apotek Hidup dan Media Penanaman Hidroponik Kepada Ibu-ibu PKK di Desa Sayang Kecamatan Jatinangor. 